\title{
Preparing the young adult with high functioning autism for the social challenges of college
}

\author{
Steven Richfield* \\ Clinical psychologist, Plymouth Meeting, Philadelphia, USA.
}

As older adolescents with Aspergers Syndrome prepare for college, many challenges await. The familiarity of high school, and the routines of daily life, have provided a secure structure for them to accomplish tasks and manage interactions with others. College presents a drastically different set of circumstances requiring skill sets that are unique to this environment. The autonomy and fragmentation of college life places a greater burden upon the student to be able to use interpersonal skills to build a successful academic and social foundation.

Although parents' roles will change from those held when their child was in high school, thoughtful preparation can ensure that the young adult continues to build an effective interpersonal repertoire. Here are some coaching tips to get the process underway:

Expand the dialogue to include the "interpersonal requirements of college." Most parents have already addressed the impact of Aspergers upon life, but now is the time to link it to college. For ease of discussion, explain how college entails more complex interactions that can be roughly divided into input and output. Interpersonal input includes comments made by and observations made of roommates, as well as conversations overheard in class or announcements made by professors. In contrast, output entails an individual's behaviors and comments that are received by others, setting the stage for all types of first impressions and final interpretations to be arrived at. Emphasize that their ability to accurately interpret input and adjust their output to send the messages they want is critical to their happiness and success in college.

Begin to share stories of how both of you received input and offered output to others in your lives. Such stories provide the Aspergers young adult with a variety of ways to enhance their repertoire. Parents might explain how despite their discomfort they asked for clarification when confused by someone's reply. Since Aspergers is marked by social ambiguities and a reluctance to pursue help, this can facilitate initiative. Similarly, if your soon-to-be college student describes social snapshots of their life you can help them consider likely interpretations of input, as well as the output that would flow well with those comments or behaviors. Most importantly, by respectfully exchanging these ideas and stories with one another, you build a trusted dialogue where your young adult with Aspergers can continue to gain vital interpersonal skills.

Preempt the typical anxiety and withdrawal that are triggered by new social settings. Aspergers tends to make people seem stiff and aloof when deep down they really want to feel attached and involved. A barrier of anxiety stands in the way, but there are ways to overcome it. One way is to ask your incoming freshman to write lists of their interests, views, recent experiences, character strengths, and goals. Such lists help them relate more spontaneously when there are opportunities to interact around such themes. Point out how news items, music and interesting classes tend to stimulate discussions so it's a good idea to be ready to meaningfully contribute to the conversations that follow. Periodically reviewing their lists gives them an "interpersonal head start" when these opportunities are presented.

Offer strategies to build interpersonal fluency and confidence. Since social life appears so amorphous to the Aspergers young adult, its best to keep strategies simple and easy to remember. One approach is to coach them in ways to "drop seeds of interest" during the opening phase of conversations. This entails briefly mentioning topics that tend to have "high interest value" to peers, such as concerts, movies, technology, or members of the opposite sex. Another strategy is to practice "good lead-ins with good timing," or using past information that has been revealed provided that the timing is right. Coach them in how information revealed during a one-on-one discussion may be inappropriate to use as a lead in during a group conversation. Discuss how as information becomes more personal, timing becomes more critical.
Copyright: (C2017 Richfield S. This is an open-access article distributed under the terms of the Creative Commons Attribution License, which permits unrestricted use, distribution, and reproduction in any medium, provided the original author and source are credited.
Correspondence to: Dr. Steven Richfield, Clinical Psychologist, Plymouth Meeting, Philadelphia, USA, Tel: 610-238-4450; E-mail: dadenuf@comcast.net

Received: June 20, 2017; Accepted: July 23, 2017; Published: July 27, 2017 